\title{
The magnetic response of hydrothermal alteration in iron-oxide basement complex, NW Nigeria
}

\author{
Joseph Ehimare Aisabokhae ${ }^{1}$, Oresajo Bamidele ${ }^{2}$ \\ ${ }^{1}$ Federal University Birnin Kebbi, Department of Applied Geophysics; Nigeria; e-mail: joseph.aisabokhae@fubk.edu.ng \\ ${ }^{2}$ Federal University Birnin Kebbi, Department of Geology; Nigeria
}

(C) 2019 Authors. This is an open access publication, which can be used, distributed and reproduced in any medium according to the Creative Commons CC-BY 4.0 License requiring that the original work has been properly cited.

Received: 14 May 2019; accepted: 27 June 2019; first published online: 30 June 2019

\begin{abstract}
Aeromagnetic data was processed in order to delineate structural trends which may be indicative of potential gold mineral traps in the Watari hill gold prospect located between longitude $5^{\circ} 8$ and $5^{\circ} 16^{\prime \prime}$, and latitude $11^{\circ} 24^{\prime \prime}$ and $11^{\circ} 30^{\prime \prime}$ in Garin Hawal district, northwest Nigeria. Landsat-8 OLI data was processed to produce colour composite, band ratio and minimum noise fraction images that mapped the hydrothermal alteration zone in the study area. The multispectral images which were displayed in Red-Green-Blue colours were subsequently pan-sharpened to display a greater image resolution of the area. The application of enhancement algorithms such as an analytic signal to the aeromagnetic data over the alteration zone helped in mapping the mafic metavolcanics, felsic metasediments and intruding granitoid complexes. Further reductions using the second vertical derivative and tilt angle derivative filters aided in delineating fracture/faults and the contact zones of the formations, especially the metasediments-metavolcanic boundary that delineates the shear zone. This study showed that the low-angle geologic structure between the metasediments and metavolcanics where hydrothermal alteration is present is likely to accommodate veins of gold mineralization in the study area.
\end{abstract}

Keywords: alteration mapping, remote sensing, shear zone, aeromagnetic data

\section{INTRODUCTION}

Alteration related to hydrothermal fluids can cause significant changes in rock magnetism, including the creation of crystalline remnant magnetism. The anomalous magnetism of the mineral itself, the alteration zone and the host lithologies is relatively common and routinely exploited during exploration. The 'highly altered' materials comprise clay, carbonate and iron hydroxide minerals; the 'intermediate' group comprises epidote minerals; and the 'unaltered' materials are mostly granitoids. Since alteration associated with mineralization normally extends over a much larger area than the mineralization itself, the magnetism can be a useful exploration vector (Gunn \& Dentith 1997).
Orogenic gold-bearing quartz veins have usually been assumed to have insignificant wall rock alteration, but research in recent years has shown that these deposits systematically align with hydrothermal alteration haloes embedded with ferric-ion and ferrous-ion bearing minerals. This can significantly expand the prospecting boundaries for mineralization during mineral exploration. Pour \& Hashim (2014) used Landsat-8 data to distinguish the mineralized alteration zone from the surrounding country rocks in a mining district in the southeast of Iran. Spectral variations associated with altered rocks caused by hydrothermal fluids can be detected on Landsat images.

Gold mineralization in host rocks in Nigeria are present in primary veins in several parts of the supracrustal belts, especially in the northwestern 
part of Nigeria, with major occurrences in Anka, Yauri and Garin Hawal areas within the basement complex. The Nigeria schist belts are Proterozoic domains of metasedimentary, metavolcanic and intrusive igneous rocks within the Pan-African belt which ramifies the West African craton and the Congo craton (Kogbe 1979). Also, studies show that the positioning of granitoids, the imposition of a general north-south foliation and eventual metamorphism observed in the region were caused by the Pan-African event at about $600 \mathrm{Ma}$. A collision-type orogeny suggested by Wright et al. (1985) involved the Pan-African region and the West African craton.

This study discusses the magnetic effects of a hydrothermal alteration zone mapped using Landsat-8 data over Garin Hawal mining district, NW Nigeria. The objectives in this research are: (i) to apply Landsat- 8 multispectral bands for delineating a hydrothermal alteration zone within the study area, (ii) to interpret aeromagnetic data for structural trend and orientation of the basement rocks; (iii) to map mineralized zones using aeromagnetic data.

\section{LOCATION AND GEOLOGY OF THE STUDY AREA}

The study area is located between longitude $5^{\circ} 8^{\prime \prime}$ and $5^{\circ} 16^{\prime \prime}$, and latitude $11^{\circ} 24^{\prime \prime}$ and $11^{\circ} 30^{\prime \prime}$. It mostly consists of the gneiss-migmatite complex, the supracrustal schist belts and the Pan-African granitoids within the Sokoto Basin, as seen in Figure 1. The gneiss-migmatite complex, yielding Archean and Early-Proterozoic isotopic ages, generally possesses an amphibolite facies grade of metamorphism (Furon 1963). They show complex structural styles and are extensively invaded by granitoid plutons of Pan-African magmatism. The granitoids are mainly syn-to-late tectonic Pan-African intrusion in granites, granidiorites and diorites with some gabbros and syenites (Wright et al. 1985).

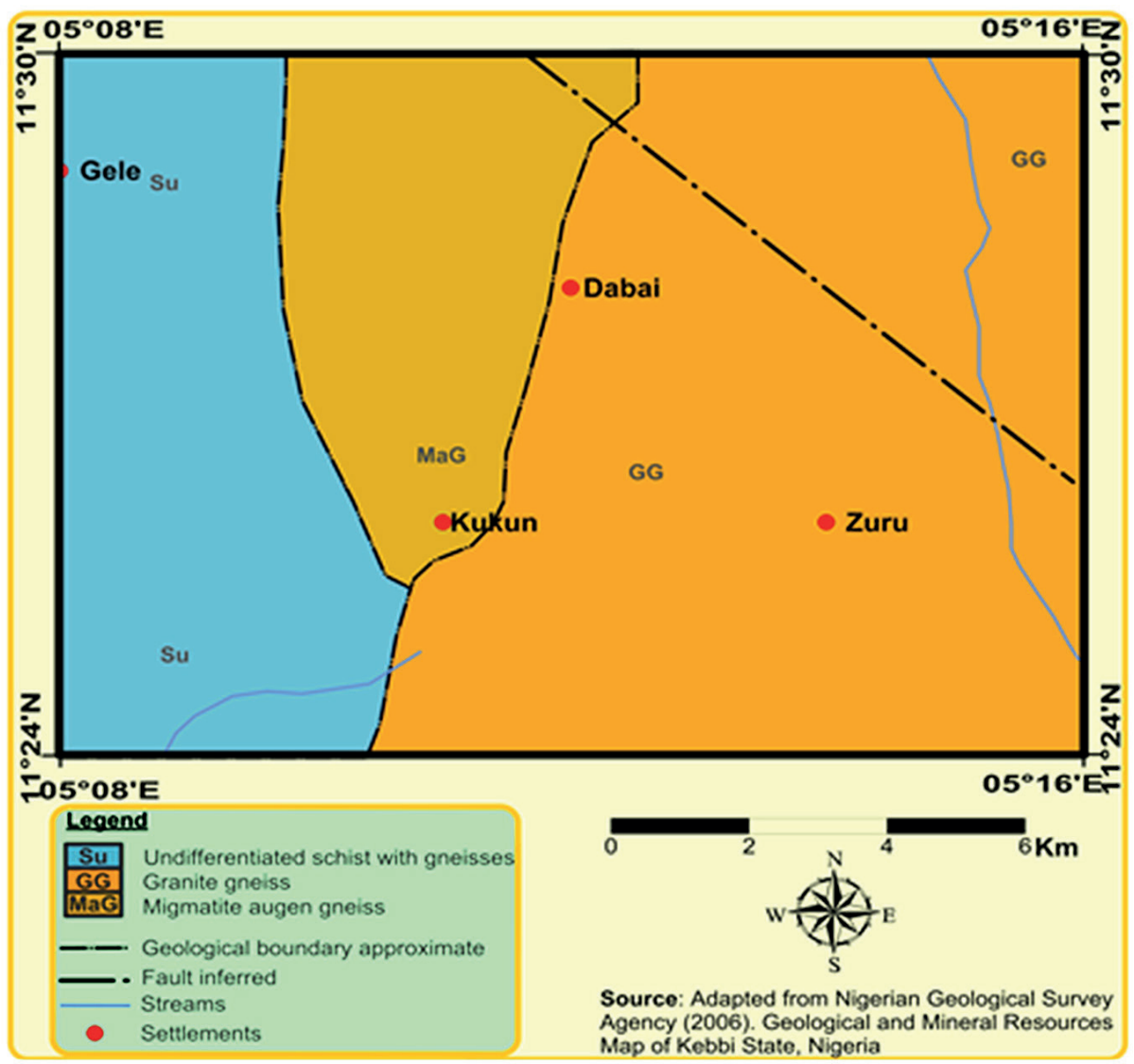

Fig. 1. Geological map of the area 
The climate is tropical, with high temperatures and rainfall for most of the year. The rainfall indices are estimated at an average annual precipitation of $734 \mathrm{~mm}$ and is marked by seasonal variation. The rainfall is concentrated in a short-wet season which extends from mid-May to mid-September whilst the dry season lasts for a much longer duration annually (Ramadan \& Mohammed 2011). During the dry season, vegetative growth is stunted. The vegetation mainly consists of dicotyledonous plants, grasses and ferns.

\section{MATERIALS AND METHODS}

The materials used for this study were an aeromagnetic map of the study area, a Landsat- 8 scene and a geologic map of Nigeria. The aeromagnetic data was obtained from the Nigerian Geological Survey Agency (NGSA). The new high-resolution airborne survey carried out for NGSA by Furgo Airborne Services in 2004 used for this study was flown at 500-meterline spacing, at an altitude of $80 \mathrm{~m}$ and terrain clearance of $75 \mathrm{~m}$.

The aeromagnetic data acquired for this study was produced in a gridded form as a total magnetic intensity (TMI) map. The geological data were digitized and georeferenced using WGS 84 Datum, UTM $31^{\circ} \mathrm{N}$ in order to use in the ArcGIS software. The aeromagnetic data was processed by means of a personal computer using the Surfer 13 and Geosoft Oasis Montaj software.

The Landsat- 8 Level 1 standard terrain corrected image with image quality of 9 was processed using the Environment for Visualizing Images (ENVI) version 5.1 software and the Environment Systems Research Institute (ESRI) ArcGIS version 10.1 software. The Landsat- 8 OLI/TIRS scene (Path 191 Row 052) dated $11^{\text {th }}$ November $(0.01 \%$ cloud cover) was acquired in 2017 and downloaded from the United States' Geological Survey archive. This data was chosen because of its rare and unique characteristics of very low cloud cover percentage and very high image quality value. Also, the date of data acquisition by USGS was put under consideration to avoid datasets captured in the period of excessive vegetation cover in the area.

\section{Magnetic data processing}

Magnetic survey data reduction is aimed at removing the effects of temporal variations in the
Earth's magnetic field that are encountered during data collection in the field. In the absence of anomalous features, unlike the gravity field, the magnetic field varies slightly with distance from the Earth. However, in the presence of crustal magnetic features, variation in the distance between the magnetometer and the Earth's surface can be of great importance (Dentith \& Mudge 2014). Also, when processing and interpreting magnetic data, a horizontal survey plane is generally assumed above the rocks, but this is not usually the case in rugged terrain.

It is common for geological controls on topography to produce strike-parallel ridges and valleys. Aerial surveying across strike causes changes in ground clearance. In order to mimic an ideal drape-flown survey, a drape correction is applied. The basis for this is a procedure known as continuation, whereby a measurement at one height can be used to determine the equivalent measurement at another height. However, continuation of data to lower heights (downward continuation) is inherently unstable and can introduce noise into the data (Dentith \& Mudge 2014). The final stage in reduction of magnetic data is levelling based on the repeat readings associated with a tie line crossing the survey lines. Errors in the magnetic levels of each data point remaining after the application of correction appear in magnetic data set as ridges parallel to the survey line direction. Levelling redistributes these around the whole dataset and any further errors are usually removed by microlevelling (Dentith \& Mudge 2014). Magnetic data can be analysed better with the application of various filters that emphasize particular characteristics of the data or suppress undesirable characteristics.

Gradients or derivatives of magnetic field data are more sensitive and reliable than the untouched TMI, so they are detail-enhancement filters. Derivatives accentuate the signatures of shallow bodies in preference to deeper-seated broader features which produce smaller gradients in the fields and are calculated from the TMI. Also, second-order derivatives such as analytic signal and tilt derivatives can be an effective form of enhancement while processing magnetic data. Their zero values coincide with the edges of sources if their edges are vertical but, more importantly, the response is localized to source edges increasing their image resolution. 


\section{Multispectral data processing}

Mineral exploration with satellite images such as the Landsat-8 Operational Land Imager is useful in the early stages of exploration. Such minerals associated with hydrothermal alteration have been studied in the laboratory for spectral signatures also identifiable from satellite images based on their reflectance properties because thematic mapping multispectral images from Landsat- 8 satellite cover the visible-to-infrared spectrum of hydrothermal alteration prospects (Pour \& Hashim 2014).

The spectral signature identification of minerals and assemblage of minerals such as hematite, jarosite and goethite formed by hydrothermal alteration, are used to identify patterns of outflows of hydrothermal systems, which can allow recognition of mineralized zones (Sabins 1999). The spectral signatures of minerals and rocks are on the basis of the work done by Hunt \& Ashley (1979) that measured the spectra of several different minerals and rocks in a laboratory (spectral signature).

In the region of solar reflected light $(0.325-$ $2.5 \mu \mathrm{m}$ ), many minerals demonstrate diagnostic absorption features due to vibrational overtones, electronic transition, charge transfer and conduction processes (Sabins 1999). Kaolinite and alunite are typical constituents of advanced argillic alteration that exhibit $\mathrm{Al}-\mathrm{OH}$ of between 2.165 and $2.2 \mu \mathrm{m}$ absorption features (Crosta \& Rabelo 1993). Porphyritically-altered rocks typically contain varying amounts of chlorite, epidote and calcite, which exhibit Fe, Mg-O-H and $\mathrm{CO}_{3}$ of $2.31-2.33 \mu \mathrm{m}$ absorption features. Iron-oxide minerals such as limonite, jarosite and hematite tend to have spectral absorption features in the visible to middle infrared from 0.4 to $1.1 \mu \mathrm{m}$ of the electromagnetic spectrum (Crosta \& De Souza Filho 2009). Hydrothermal silica minerals typically consist of quartz, opal and chalcedony. Thermal Infra-red (TIR) emissivity spectral illustrate that quartz and opal contain a prominent feature in the $9.1 \mu \mathrm{m}$ region (Crosta \& De Souza Filho 2009).

All Landsat imagery is composed of grayscale images corresponding to associated spectral bands as seen in Table 1 . When a composite of three bands (red, green, and blue) is created, a colourful multispectral image will emerge, which can be true colour or false colour (in this case, a NIR band is used instead of blue band). There are diverse possible band combinations depending on the processing channel with regards to the result envisaged.

A colour composite with the visible bands of the spectrum that correspond to red, green and blue, is called a true colour composite. When a composite is created with non-visible bands it is called a false colour composite image. In a false colour image, the combination of three bands (visible bands and infrared bands or only infrared bands) in red, green and blue (RGB) will produce an image that enhance some characteristics depending on the selected spectral bands. The bands are assigned based on the spectral properties of the rocks and alteration minerals in the study area.

Table 1

Landsat 8 Operational Land Imager (OLI) and Thermal Infrared Sensor (TIRS) bands characteristics (USGS 2015)

\begin{tabular}{|l|c|c|}
\hline \multicolumn{1}{|c|}{ Bands } & $\begin{array}{c}\text { Wavelength } \\
{[\boldsymbol{\mu m}]}\end{array}$ & $\begin{array}{c}\text { Ground Sampling Distance } \\
{[\mathbf{m} / \mathbf{p x}]}\end{array}$ \\
\hline Band 1 - Coastal aerosol & $0.43-0.45$ & 30 \\
\hline Band 2 - Blue & $0.45-0.51$ & 30 \\
\hline Band 3 - Green & $0.53-0.59$ & 30 \\
\hline Band 4 - Visible Red & $0.64-0.67$ & 30 \\
\hline Band 5 - Near Infrared (NIR) & $0.85-0.88$ & 30 \\
\hline Band 6 - SWIR 1 & $1.57-1.65$ & 30 \\
\hline Band 7 - SWIR 2 & $2.11-2.29$ & 30 \\
\hline Band 8 - Panchromatic & $0.50-0.68$ & 15 \\
\hline Band 9 - Cirrus & $1.36-1.38$ & 30 \\
\hline Band 10 - Thermal Infrared (TIRS) 1 & $10.60-11.19$ & $100^{\star}(30)$ \\
\hline Band 11 - Thermal Infrared (TIRS) 2 & $11.50-12.51$ & $100^{*}(30)$ \\
\hline
\end{tabular}

* TIRS bands are acquired at 100-meter resolution but are resampled to 30 meters in final data product 
Usually, image enhancement is required for a better interpretation of the outcrop geology of the study area. This operation consists of a stretch imagery contrast aimed at improving the information content and spatial resolution of the image. Spatial filtering techniques provide better visualization, highlighting or suppressing some features of the image that helps to extract geological features. These filters work based on spatial frequency, so rapid variations in brightness levels can indicate roughness and low spatial frequency smother areas (Green et al. 1988). Image processing methods transform the multispectral satellite data into images that enhance geological features in contrast with the surrounding rocks. Enhancement techniques such as band composite, band ratio and minimum noise fraction (MNF) can be applied to allow the extraction of spatial and spectral information related to lithology, structures, hydrothermal alteration, and others.

\section{RESULTS AND DISCUSSION}

The results of data processing in this study are the images that were produced from the reduction, stretching and enhancements of the input data. Landsat- 8 data produced images for colour composite, band ratio and minimum noise fraction while the TMI, analytic signal, second vertical derivative (2VD) and tilt derivative images where produced from the aeromagnetic data.

\section{Colour composite}

For the purpose of highlighting geologic features and accentuating textural characteristics at a regional scale, a combination of three bands is assigned the natural colours of Red-Green-Blue (RGB) on the Landsat-8 image. A remote sensed image comprises of a digital number (DN) for each pixel (Mackey 2005). The pixel DN is a linearly transformed representation of at-sensor radiance for a discrete resolved area of the Earth's surface. It is possible to convert at-sensor radiance to at-sensor spectral reflectance. However, at-sensor reflectance still has an atmospheric scattering effect. In this study, the scattering effect was corrected to produce a surface reflectance image by applying semi-empirical modelling using ENVI program which involved imputing atmospheric constants for latitude/longitude and date of acquisition of the Landsat scene. Figure 2 is the surface reflectance image showing the false colour combination of the study area.

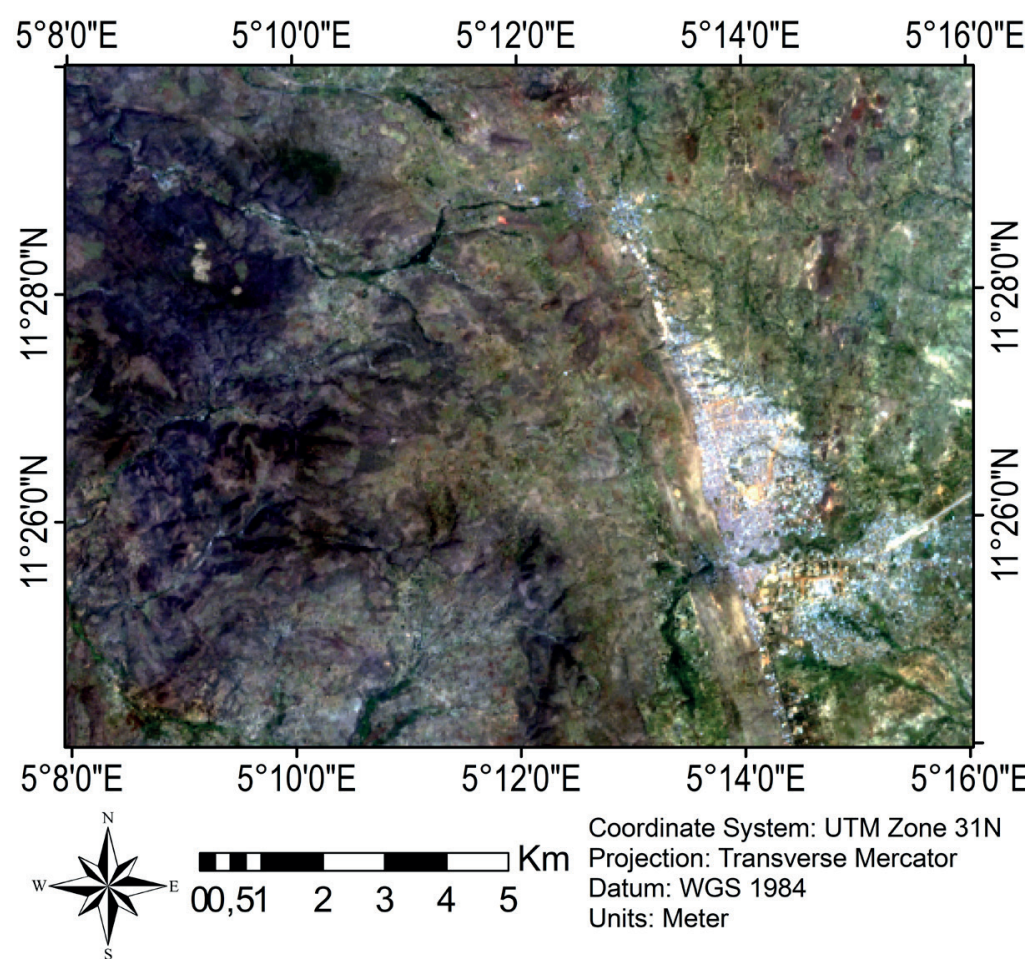

Fig. 2. False colour composite of Landsat-8 data 
This image which displays band 432 in RGB composite was produced by importing individual 8-bit gray-scale surface reflectance bands of the multispectral data into ENVI workspace. The operation was then followed by calculating the Optimal Index Factor to select the most informative colour composite image using ILWIS software. Having all the bands ranked according to their respective spectral quality, the brightest bands were then combined and displayed in RGB using the ENVI software.

\section{Band ratio}

It is possible to divide the digital number of one band by the digital number of another band in an operation known as band ratio. The surface reflectance data comprises a series of spectral bands, the pixels of which each have a digital number (Mackay 2005). The operation of dividing one band by another band of the surface reflectance data actually depicts the ratioing of the $\mathrm{DN}$ of one band by the $\mathrm{DN}$ of another band on ENVI software. This procedure is instrumental in highlighting certain features or rocks that cannot be seen in the individual raw bands. This operation involves the selection of the band with high reflectance for a mineral as the numerator while setting any other band with high absorption of that same mineral as the denominator in the band ratio interface within the ENVI program. Three distinct ratios were performed namely; which were finally assigned to Red-Green-Blue respectively. The ratio is useful for mapping iron oxides such as hematite, limonite and jarosite because it has absorption in the blue region and high reflectance in the red region. The ratio was used for mapping iron-hydroxide minerals because most of those minerals have high reflectance within the wavelength of band 5 while ratio accentuates the spectral features of most carbonate minerals. Figure 3 is a stretched image resulting from filter operations performed on the band ratio image. This operation is performed on the ENVI software for the purpose of reducing dimensionality on the band ratio image as a pre-step towards minimum noise fraction.

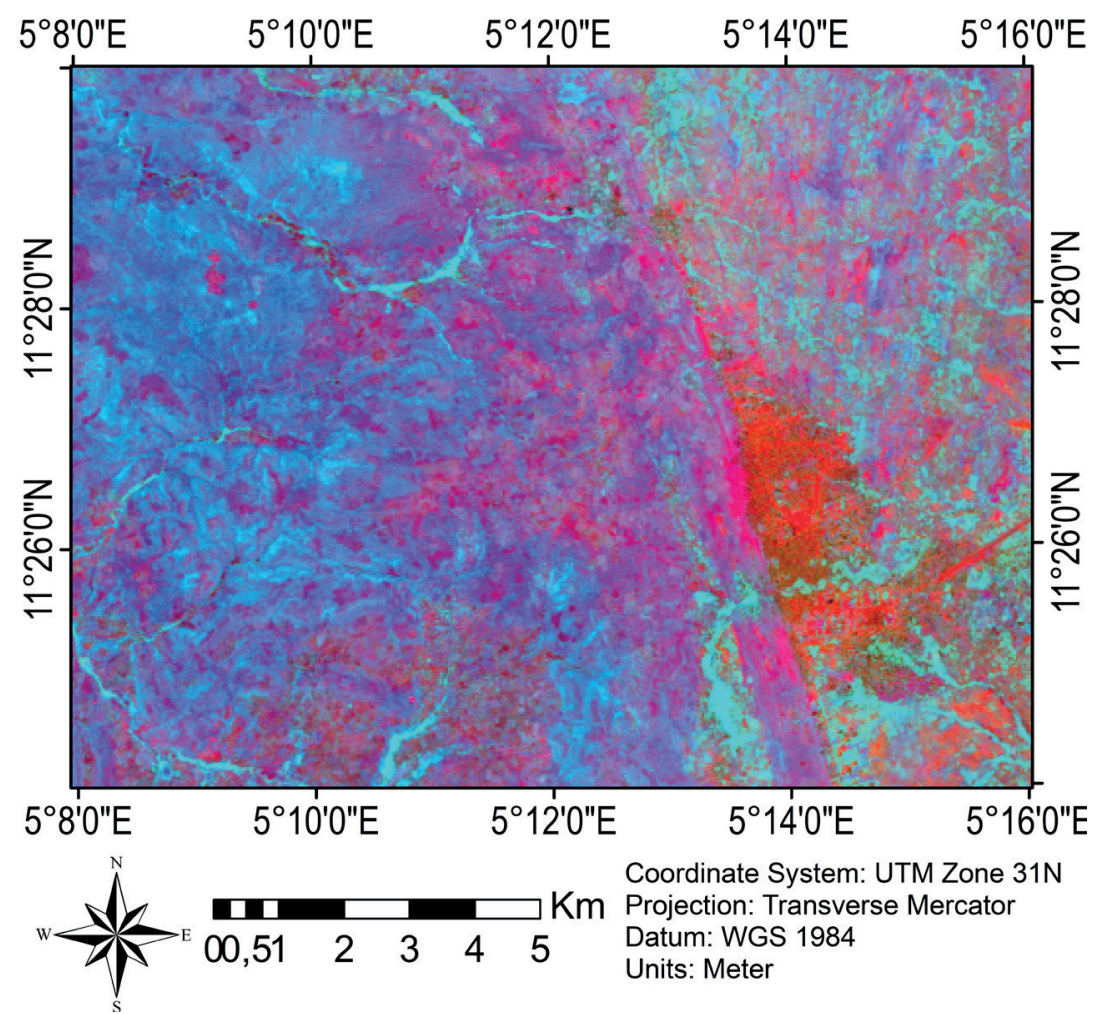

Fig. 3. Band ratio image for hydrothermal alteration mapping of the area 


\section{Minimum noise fraction}

This method which was developed by Green et al. (1988) is similar to principal component orthogonalization rotation that results in components ordered in increasing rank of random noise rather than decreasing rank of variance. So, the minimum noise fraction (MNF) transform is used to determine the inherent dimensionality of image data, to segregate and equalise the noise in the data, and to reduce the computational requirements in the case of subsequent processing. This technique was used in Figure 4 to identify hydrothermally altered rocks (red) in the image with the help of the pan-sharpening technique. MNF was performed in this study to extract individual mineral species from a mixed pixel spectrum, in theory providing the geologist with the capability to map mineral surface composition.

The MNF approach for the analysis of multispectral data used in this work is implementable and documented within the ENVI software system. The analysis approach consists of spectral compression, noise suppression and dimensionality reduction using the minimum noise fraction transformation. MNF component images show steadily decreasing image quality with increasing band number, so images with higher eigenvalues contain higher spectral information (Green et al. 1988). RGB colour combination image was assigned to three high eigenvalues MNF transformed bands.

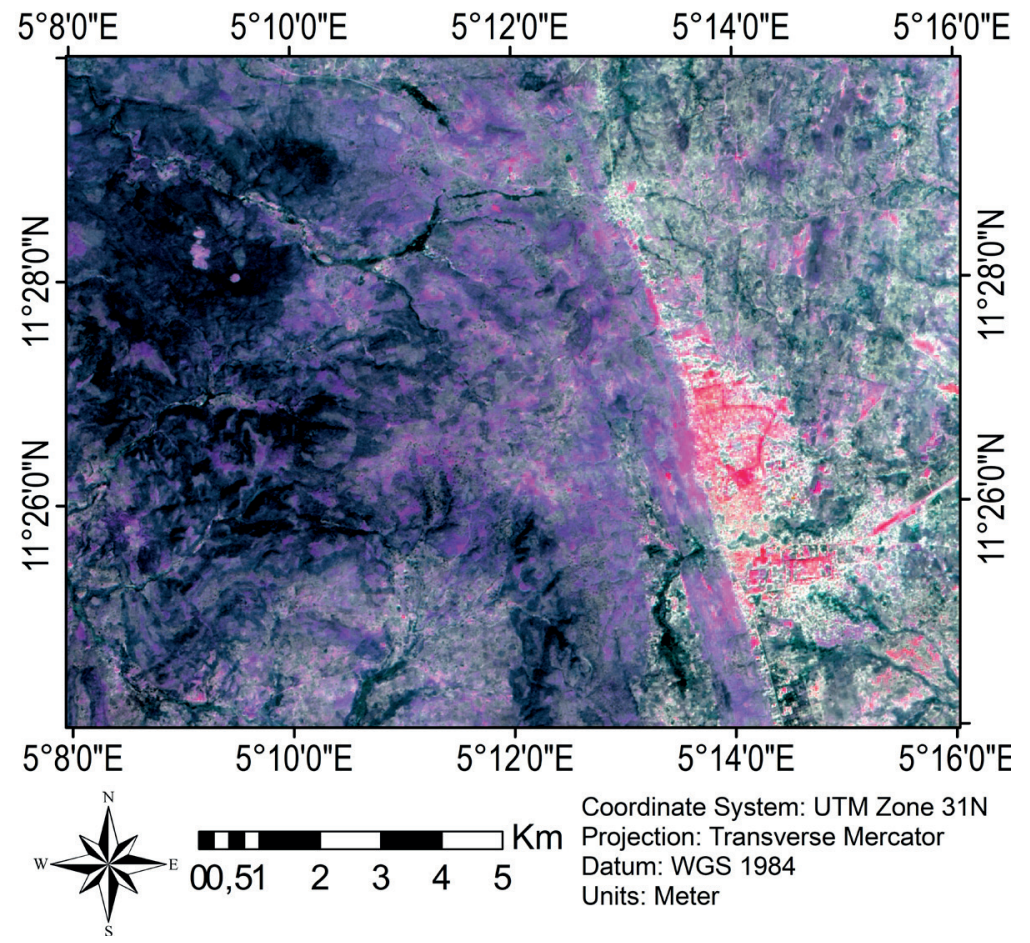

Fig. 4. Pan-sharpened RGB image for MNF 123 of the area

\section{Total magnetic intensity map}

The total magnetic intensity (TMI) map in Figure 5 displays the wavelength and magnetic intensity inherent in the study area. In the analytic signal map, metasediments $(\mathrm{Cz})$ in the north-western segment of the region (Fig. 6) displayed average to low magnetic intensity as a result of supposed poor accumulation of magnetite minerals. The area Ax appears to be a contact zone of metavolcanics with intruding granitoids in the north-eastern part. There is an increase magnetic presence that interposes the metasediments formed around the south-western portion of the region. 


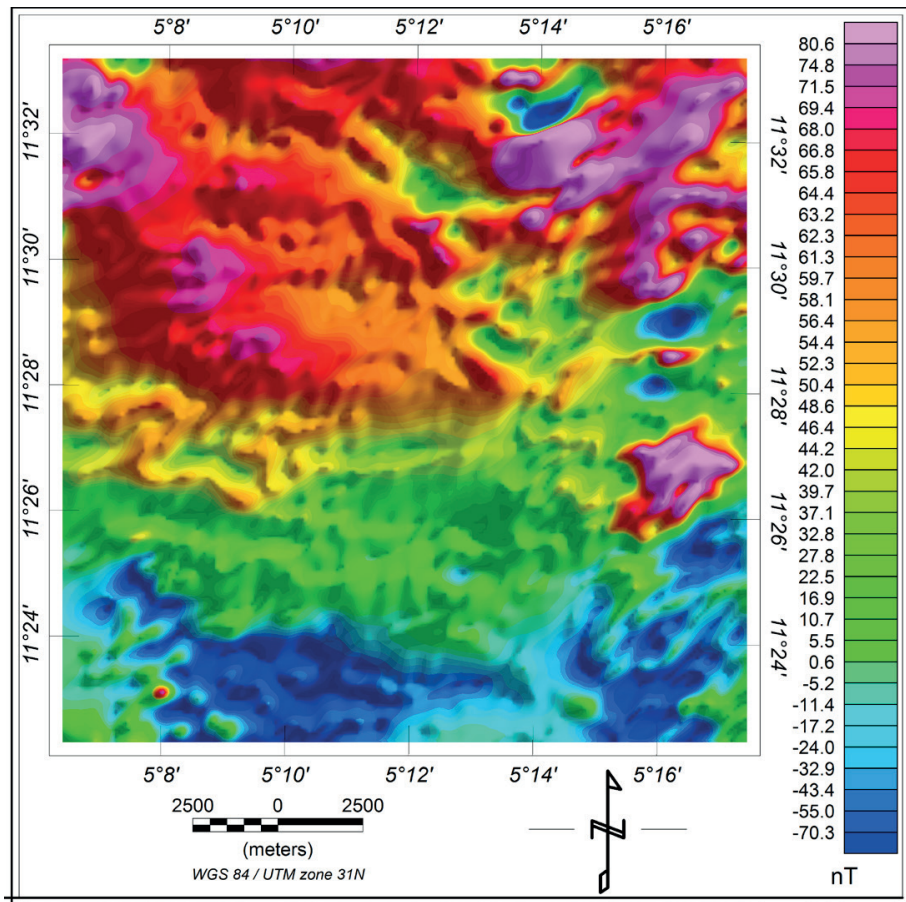

Fig. 5. Total magnetic intensity map of the area

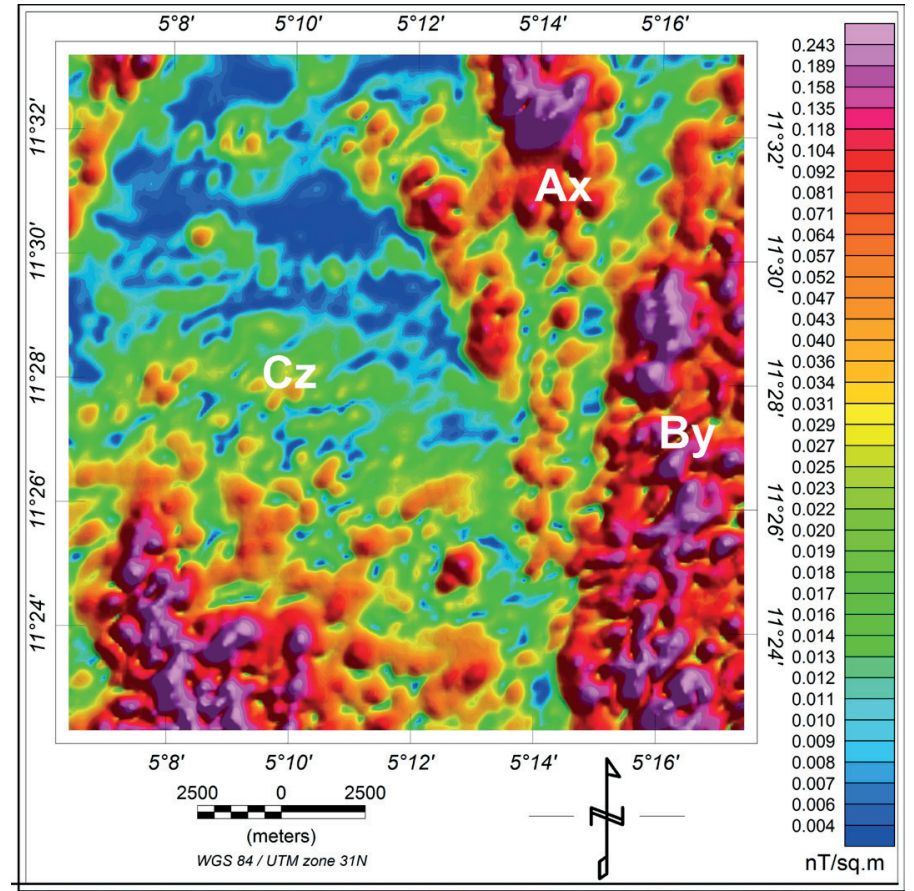

Fig. 6. Analytic signal map of the area

The area of contact of the metavolcanics (By) and metasediments $(\mathrm{Cz})$ recorded medium-to-low magnetic anomaly. This low-angle fault structure which serves as the meeting point between $\mathrm{By}$ and $\mathrm{Cz}$ is a prospective auriferous zone hosting veins of gold mineralization. There may have been an occurrence of a demagnetisation process resulting in reduced magnetic influence due to hydrothermal fluid migration within cavities, especially within the multiple fault structures formed around the shear zone. 


\section{Magnetic derivative maps}

Destructive interference and the superimposition of magnetic anomalies can be significantly improved upon to produce greater resolution of wavelength features of the magnetic field with the application of vertical derivative filters. By comparing and contrasting the 2VD map in Figure 7 with the TMI map in Figure 5, a better resolution of structural features such as regional fault (white broken line) and local fault (black line), especially in the southern part of the study area, is achieved.

The Garin Hawal shear zone, which is a Proterozoic domain, is a zone of regional prominence acting as the boundary between the metasediments and metavolcanic rocks in which regional structures of faults and fractures are displayed as seen in Figure 8. These fractured zones and faults structures, which are relays of the regional shear zone system, are likely continental-scale trans-current faults, and potential deep-tapping crustal faults significantly influencing the localization of hydrothermal residue with its role as duct for hydrothermal fluid deposition. Intrusion of granitoids is suspected to have been guided by structure reactivation around the shear zone featuring a number of cross-cutting faults oriented primarily in the NE-SW and E-W directions indicating the episodes of tectonic activities associated with the Precambrian basement complex.

The vector of granitoid intrusion may have resulted in faulting and fracturing within the metavolcanics, especially around its boundary with the metasediments in the area.

Several structures comprising faults and fractures have surfaced by the application of second vertical derivative and tilt angle derivative filters presented in Figure 7 and Figure 8 respectively. Mineral-forming hydrothermal fluids transmitted along fault structures is capable of transmitting heat, which may demagnetize the country rocks resulting in low magnetic signatures as seen around some possible auriferous mineral conduits in the area.

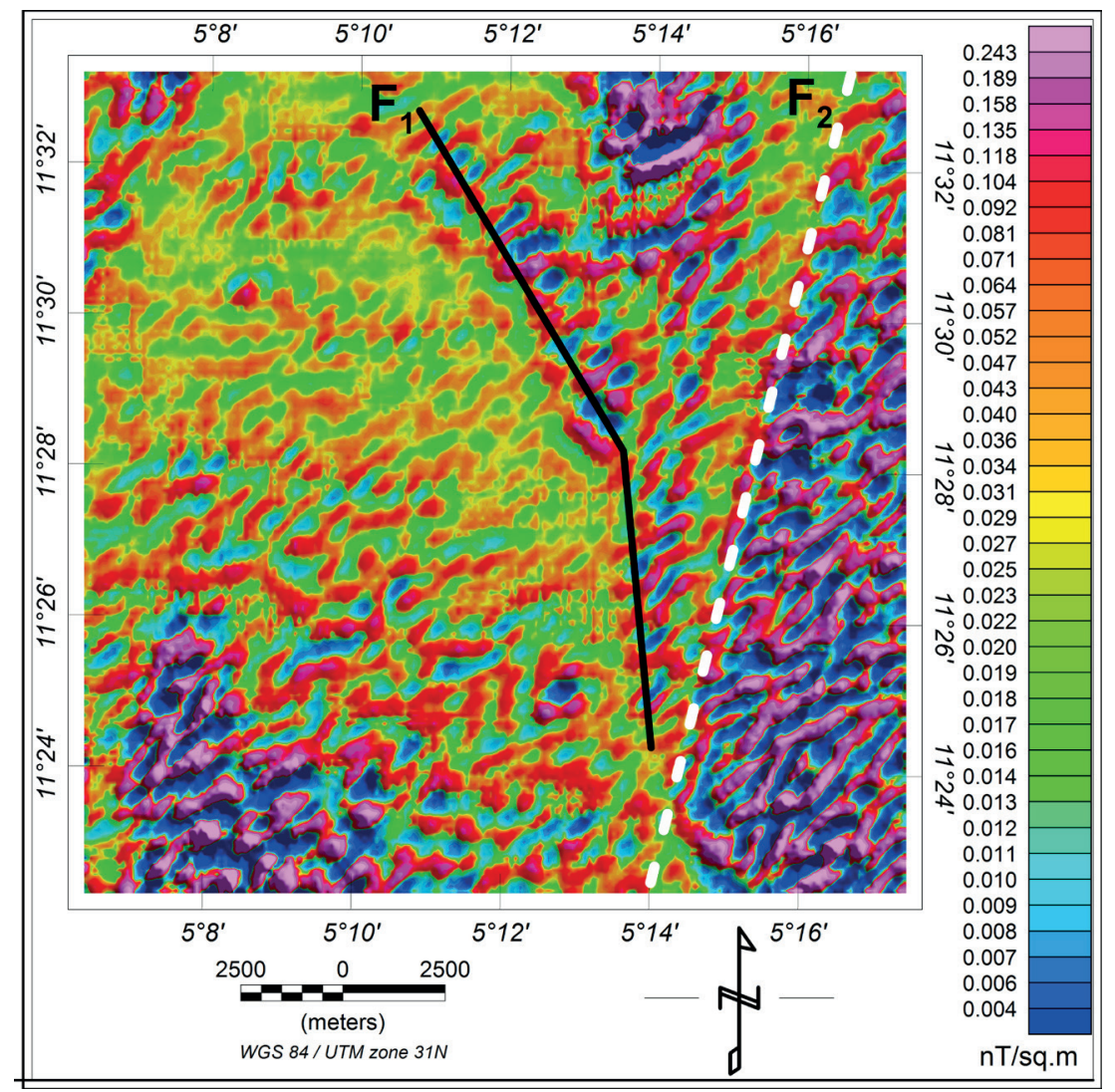

Fig. 7. Second vertical derivative map of the area 


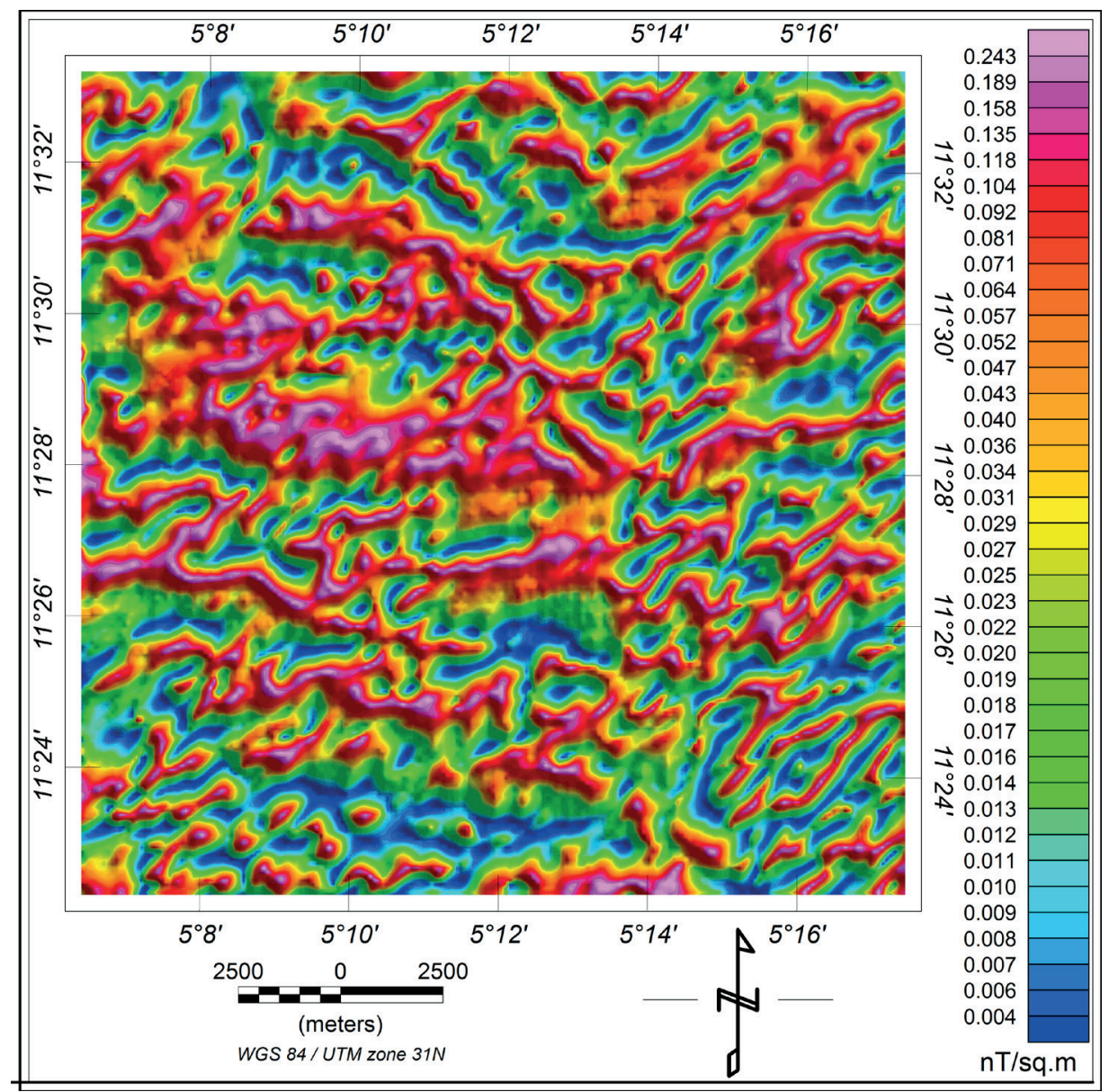

Fig. 8. Tilt derivative map of the area

\section{Geological and structural map}

The result of the second vertical derivative (Fig. 7) was reduced to $50 \%$ opacity and superimposed on the band ratio image as seen in Figure 9. The alteration zone (AZ) which appears as red pigmentation on the band ratio map (Fig. 3) is delineated by broken white lines and is bordered on its left by a low angle fault $\left(F_{1}\right)$ as seen in Figure 7 . The fault clearly depicts the boundary between contrasting magnetic imprints interpreted to be metasedimentary and metavolcanic rocks as seen in the analytic signal map. The fault which can also be seen on the Landsat map is a regional trans-current lineament with the suitability to transmit hydrothermal fluids resulting in alteration haloes due to weathering. The $\mathrm{F}_{2}$ fault marked by a white broken line on the aeromagnetic map is a deep crustal fault that does not extend to the surface of the
Earth, hence its non-appearance on the Landsat image.

Important control features of geological relevance extracted from the magnetic data and Landsat- 8 data have been co-opted to generate a proposed geological map of the study area as seen in Figure 10. The lateral extent of mapped hydrothermal alteration zone associated with structures suspected of hosting subsurface mineral veins was delineated.

The zone extends to beyond $5 \mathrm{~km}$ over the region of low angle of a fault at the boundary between the metasediments (MS) and the metavolcanics (MV). Two major fault structures $\left(\mathrm{F}_{1}\right.$ and $\left.\mathrm{F}_{2}\right)$ extend for several kilometres trending from NE to SW. The major fault $\left(\mathrm{F}_{1}\right)$ structure in the area believed to be mineralized is characterized by intense hydrothermal alteration, metasomatism and veining. 


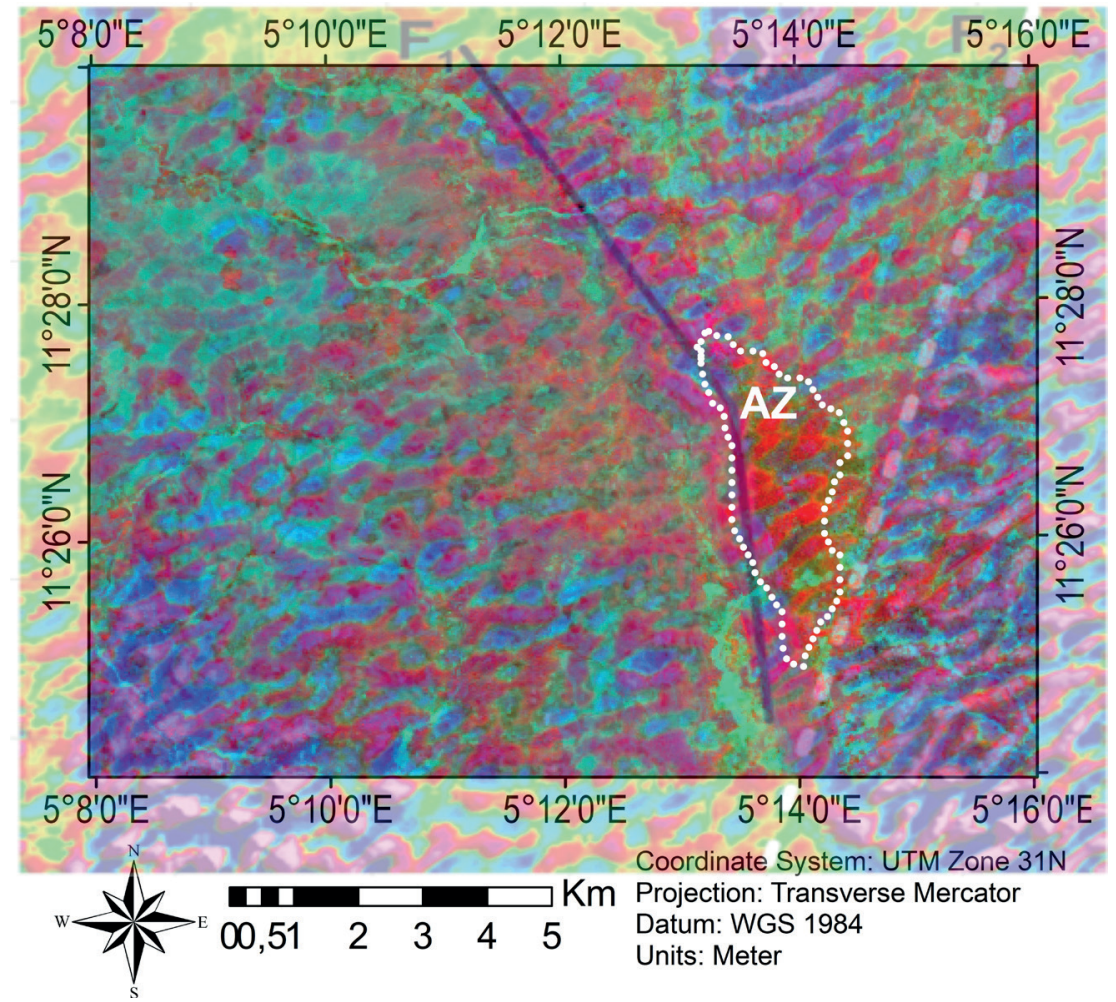

Fig. 9. Vertical derivative map superimposed on a band ratio map

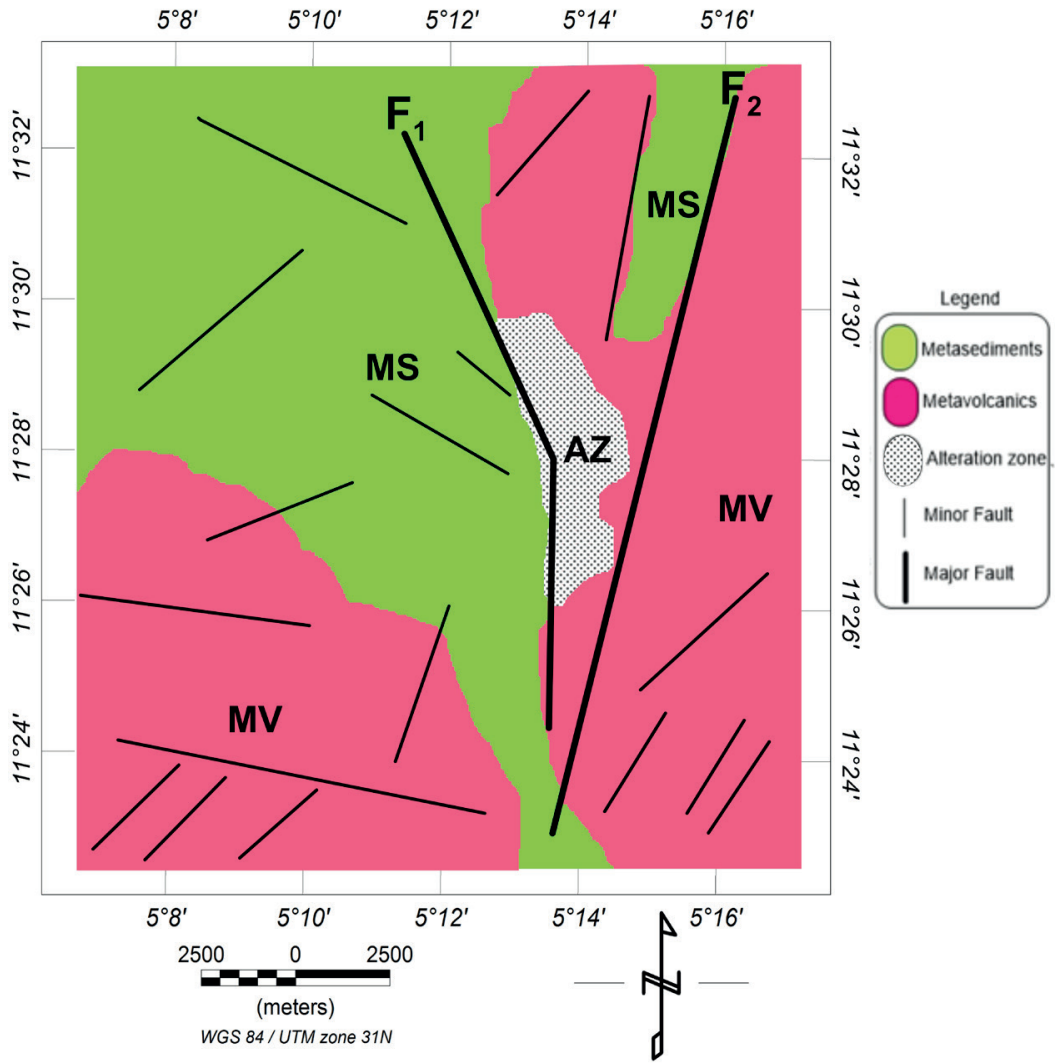

Fig. 10. Structural and geological extract from integrated data 


\section{CONCLUSION}

In this study, the main intention was to map the magnetic fabrics over the hydrothermal alteration signatures delineated using Landsat- 8 data in the Garin Hawal gold mining district, NW Nigeria. Landsat images were applied to delineate hydrothermally altered rocks using the band ratios technique and which produced distinctive reflection features of iron-hydroxide minerals. The features corresponded to minerals associated with alteration haloes and represented surface expression for in-vein auriferous deposits. Furthermore, aeromagnetic data over the study area were subjected to filtering techniques which included second order vertical, analytic signal and finally, tilt angle derivative to display the magnetic imprints of the zone. A proposed geological map produced from the integration of the Landsat- 8 and aeromagnetic datasets was helpful in authenticating the multispectral lithological mapping of the area in tandem with the aeromagnetic data. The zone of inferred mineralization correlates perfectly between both datasets, thus proving the ability of such an integrated approach to map structures and minerals of interest on a regional scale.

This study was supported by a grant from the Tertiary Education Trust Fund (TETFUND), Nigeria through its FUBK/2018/BATCH6 RP/9 intervention.

\section{REFERENCES}

Crosta A. \& De Souza Filho C., 2009. Mineral exploration with Landsat Thematic Mapper (TM) / Enhanced Thematic Mapper plus (ETM+): A review of fundamentals, characteristics, data processing, and case studies. Review in Economic Geology, 16, 59-82.

Crosta A. \& Rabelo A., 1993. Assessing of Landsat TM for hydrothermal alteration mapping in central western Brazil. [in:] Proceedings of the Ninth Thematic Conference on Geologic Remote Sensing: Exploration, Engineering, and Environment: 8-11 February 1993, Pasadena, California, USA, Environmental Research Institute of Michigan, 53-61.

Dentith M. \& Mudge S.T., 2014. Geophysics for the Mineral Exploration Geoscientist. Cambridge University Press, Cambridge, United Kingdom.

Furon R., 1963. Geology of Africa. Oliver and Boyd.

Green A.A., Berman M., Switzer P. \& Craig M. D., 1988. A transformation for ordering multispectral data in terms of image quality with implications for noise removal. Geoscience and Remote Sensing, 26, 1, 65-74.

Gunn P.J. \& Dentith M.C., 1997. Magnetic responses associated with mineral deposits. ASGO Journal of Australian Geology and Geophysics, 17, 2, 145-158.

Hunt G.R. \& Ashley P., 1979. Spectra of altered rocks in the visible and near infraraed. Economic Geology, 74, 16131629.

Kogbe C., 1979. Geology of the south-eastern sector of the Iullemmeden Basin. Bulletin of Department of Geology, Ahmadu Bello University, Zaria, 2, 1, 44-63.

Mackay L., 2005. Earth observation and GIS of the physical environment. Lecture series 4 - School of Geography, University of Leeds, United Kingdom, [on-line:] https://www.coursehero.com/file/22033398/Lecture4 [access: 10.05.2019].

Pour A.B. \& Hashim M., 2014. Hydrothermal alteration mapping using Landsat- 8 data, Sar Cheshmeh copper mining district, SE Iran. Journal of Taibah University for Science, 9, 155-166.

Ramadan T.M. \& Mohammed F.A., 2011. Characteristics of gold mineralization in Garin Hawal area, Kebbi State, NW Nigeria, using remote sensing. The Egyptian Journal of Remote Sensing and Space Science, 13, 153-163.

Sabins F., 1999. Remote sensing for mineral exploration. Ore Geology Review, 14, 157-183.

USGS, 2015. Landsat-8 (L8) Data Users Handbook. Version 1.0.

Wright J.B., Hastings D.A. \& William H.R., 1985. Geology and mineral resources of West Africa. Allen and Unwin, London. 